\title{
LA VERDAD ESTÁ EN LOS HECHOS: UNA TENSIÓN ENTRE OBJETIVIDAD Y OPOSICIÓN. RADIO COOPERATIVA EN DICTADURA
}

\begin{abstract}
En el siguiente artículo se analizan las distintas estrategias periodísticas de la radio Cooperativa que permitieron su instalación en la industria comunicativa como un medio de oposición. La construcción de la identidad de la emisora se sustentó a partir de un discurso de "objetividad" que promueve durante el régimen militar. Se postula, por una parte, que el consagrado éxito se debió al contexto de represión y censura a que se vieron expuestos los medios de comunicación, transformando a la información en un tema político que no pasaba por las posiciones partidistas o ideológicas definidas, sino por el solo hecho de informar los acontecimientos que eran silenciados. Para este cometido se revisaron los Archivos de la Vicaría de la Solidaridad, los Archivos de la emisora en cuestión y los Archivos del Colegio de Periodistas, entre otras fuentes bibliográficas.
\end{abstract}

Palabras clave: Radio Cooperativa, estrategias periodísticas, objetividad periodística, identidad radial.

The following article analyzes the different journalist strategies followed by Radio Cooperativa that allowed its positioning as an opposition media within the communication industry during the dictatorship. The construction of its identity was built upon a discourse of objectivity promoted during the military regime. The radio's success was due to its strategy of informing about facts that were silenced in a context of repression and censorship. This transformed information into a political theme that was not influenced by political parties. To accomplish this, several archival sources were revised including the Vicaría de la Solidaridad Archives, Cooperativa Radio archival materials as well as Colegio de Periodistas records.

Key words: Radio Cooperativa, journalist strategies, journalistic objectivity, radio identity.

Fecha de recepción: mayo 2007

Fecha de aceptación: diciembre 2007

\footnotetext{
1 Candidata a doctora en Historia por la Pontificia Universidad Católica de Chile, 2008. Se agradece por todos los comentarios, críticas y revisiones a Javier Osorio, Steve Stern, Alfredo Riquelme y Patricio Bernedo, cuyas sugerencias fueron de gran utilidad para llevar a cabo esta investigación. Correo electrónico: cariver2@uc.cl
} 


\section{PRESENTACión}

"Todo observador de los acontecimientos humanos contemporáneos es también un participante en ellos, $\mathrm{y}$, en consecuencia, está involucrado moralmente en ellos..."

ARNOLD TOYNBEE

El 13 de mayo de 1983 los programas noticiosos de la Radio Cooperativa Vitalicia de Santiago, Temuco y Valparaíso fueron suspendidos indefinidamente mediante el Decreto Supremo 593 firmado por el ministro del Interior, el Sr. Sergio Onofre Jarpa. La División de Comunicación Social (DINACOS) ${ }^{2}$ señaló a los medios que tal medida se tomó debido a la tergiversación de la información respecto a las agitaciones del once de mayo que habría realizado la emisora, a través de entrevistas, comentarios, noticias y transmisiones de toda índole, con la clara intencionalidad política de crear un clima artificial de agitación y de efervescencia pública. Ese mismo día en que la señal informativa de Cooperativa se apagó del dial, el apoyo desde distintos sectores de la sociedad se hizo sentir públicamente. El Colegio de Periodistas, la Comisión de Derechos Humanos, los estudiantes de la Universidad de Chile, las asociaciones gremiales, e incluso la Iglesia católica, hicieron causa común por recuperar la voz de una de las radios con más auditores a lo largo de Chile ${ }^{3}$.

Las demandas por la reapertura de la emisora se expresaron a través de actos de solidaridad con todos los medios que, en más de alguna ocasión, habían visto sus informativos suprimidos o restringidos, debido a su defensa de la democracia y su oposición al régimen ${ }^{4}$. Asimismo, a través de estos actos, la sociedad civil reclamaba y demandaba por un espacio que, de alguna forma, les devolvía el sentido de pertenencia a una comunidad que había sido desintegrada por la dictadura.

Cooperativa, en efecto, se había instalado en el imaginario colectivo como la radio de todos los chilenos. Las tres mil firmas y mensajes que se reunieron hasta el momento en que se levantó la suspensión, estremecieron a todos los integrantes de la emisora, quienes no podían creer el impacto social que provocaba una radio

2 La Dirección Nacional de Comunicación Social del Gobierno (DINACOS) fue un órgano dependiente de la Secretaría General de Gobierno creado por la Junta Militar, entre cuyas funciones se encontraba la de asesorar al ministerio en la formulación de políticas de comunicación, y la de "supervisar la fundación, edición y publicación, circulación, distribución y comercialización en cualquier forma de nuevos diarios, revistas, periódicos e impresos en general”. En la práctica, ello significaba que DINACOS, además de fiscalizar los contenidos que se publicaban, también era la encargada de otorgar o negar los correspondientes permisos para el surgimiento de los medios de comunicación.

Archivo de la Vicaría de la Solidaridad. Resumen de Prensa 1983. "Suspensión de los informativos de la Radio Cooperativa", 28-30. Para efectos de abreviatura, el respectivo archivo se enunciará con la siguiente sigla AVSCH.

4 En diciembre de 1982, la revista Apsi fue clausurada por nueve meses. Esto le significó, además de costos económicos, la restricción de informar solo sobre materias internacionales. Para la publicación escrita quedaba prohibido el emitir información alguna sobre el contexto nacional. Ana María Foxley, "Seguiremos profundizando la misma línea", Revista Hoy, Santiago, del 10 al 16 de marzo, 1983, sin página. 
que había renunciado a defender una opinión propia mediante comentarios o editoriales, que se negaba a cerrar filas con los partidos políticos de oposición, y cuyo único objetivo era presentar todos los hechos desde el punto de vista de los protagonistas, independiente del bando político del que estos provinieran ${ }^{5}$. De hecho, Cooperativa diseñó sus estrategias comunicativas ${ }^{6}$ a partir de un discurso basado en la objetividad periodística ${ }^{7}$, característica determinante de la prensa moderna liberal, instalándose en el mercado informativo como un medio "neutral", cuyo fin es informar a la población, independientemente del sector político al que se adscribiera. Sin embargo, en un régimen de restricciones, el discurso de objetividad deviene en una postura de oposición, por cuanto no solo cualquier crítica, sino también la propia información no controlada era vista por la autoridad como una amenaza y, por los lectores, como una forma de resistencia ${ }^{8}$.

Los discursos informativos radiales de Cooperativa produjeron, de este modo, efectos de realidad no vinculados mecánicamente con los principios empíricos que constituyeron su referente; es decir, las representaciones producidas por la radio -que no buscaban ni alentar a las masas ni generar un espacio de confrontación explícito como se pensaba- permitieron que la sociedad pudiera dar cuenta de sí misma a partir de una particular construcción de sentido, en la cual intervinieron gramáticas de producción y de reconocimiento entre sus auditores. Cooperativa, al igual que otros medios disidentes, ayudó de esta forma a reconstituir una memoria

5 En las rondas de prensa, Luis Ajenjo (gerente general de la emisora en el período) señala: "Estamos impresionado por esa solidaridad. Esta es una radio que incluso renunció a tener opinión propia, como comentarios o editoriales, a fin de dar cabida a todos los hechos y a los puntos de vista de los protagonistas de esos hechos". Ignacio González Camus, "Radio Cooperativa. Silencio noticioso". Hoy, Santiago, 25 al 31 de mayo, 1983, 14-15.

6 Entendemos por estrategia periodística el "conjunto de objetivos y definiciones políticas, periodísticas y empresariales que, combinadas entre sí, le dan un perfil propio al medio". Es decir, son definiciones y acciones prácticas que ubican a un medio dentro del contexto sociocultural, le dan una identidad, una función en el escenario de las comunicaciones y una situación dentro del mercado de la información. Cfr. Eduardo Santa Cruz, Modelos y estrategias de la prensa escrita en procesos de modernización: Chile siglo XX, Documentos de trabajo, Santiago, Centro de Investigaciones Sociales, Universidad Arcis, 1996, 4.

7 Para el periodismo, la objetividad deviene como un factor relevante en la conformación de su discurso a partir del siglo XIX, principalmente desde la irrupción del proceso de masificación de los públicos. El discurso de la objetividad, concepto acuñado por el positivismo, permite convocar a distintos tipo de lectores que dotan de legitimidad al periodismo a través del desarrollo de formas y estilos que se traducen en un relato de los acontecimientos que sean válidos para todos y no solo para algunos sujetos. De esta manera, la objetividad opera como una estrategia retórica y, a su vez, comercial. Por lo mismo, la objetividad periodística no se presenta como el resultado de una reflexión epistemológica, sino que, muy por el contrario, es el resultado de la nueva estrategia comercial que surge a principio de siglo XX, y la cual se asume rápidamente como un valor periodístico. Es decir, se transforma en un concepto ético. La "doctrina" de la objetividad se puede comprender desde tres planos: el plano deontológico, en tanto es un "deber" ser o compromiso ético; el plano de la investigación periodística, en tanto exige un conjunto de normas procesales, y el plano de las retóricas, en tanto se trata de un conjunto de reglas de naturaleza estilísticas. Cfr. Mario Mesquita, El cuarto equívoco. El poder de los media en la sociedad contemporánea, Madrid, Editorial Fragua, 2007. Michel Schudson, Discovering the news. A social history of American Newspaper, New York, Basic Books, 1979. Gaye Tuchman, La producción de noticias, Barcelona, GG Mass Media, 1983.

8 Juan Pablo Arancibia, Comunicación Política. Fragmentos para una genealogía de la mediatización en Chile, Santiago, Editorial ARCIS, 2006, 136-137. 
colectiva -distinta a la de "salvación de la patria" que acuñó el régimen militar para legitimar su presencia-, redefiniendo y revalidando la sensación de pertenencia de los distintos individuos a una comunidad supragrupal, nacional y colectiva, que había sido mutilada y dividida por el régimen militar ${ }^{9}$.

En esta construcción de valores y creencias colectivos, los medios juegan un rol relevante. Ellos permiten estructurar y organizar la presencia del pasado en todos los ámbitos de la vida contemporánea. Por un parte, son los depósitos donde se archivan las memorias, en la medida que son capaces de registrar y reproducir los acontecimientos de una época. Por otra parte, estos registros memorables son construcciones que se dan en la dialéctica entre recordar-olvidar, en la cual confluyen de manera dinámica los intereses de los productores (tanto del propio medio como de los periodistas) y del público receptor. La memoria, de esta forma, no es solo el relato de los acontecimientos pasados, sino también la construcción en el presente de aquello que es posible conocer y de aquello que se debe recordar, es decir, de aquello que consideramos como "lo" memorable. De este modo, cabe preguntarnos ¿cuál fue la responsabilidad de los medios en el régimen autoritario? O, dicho de otra forma, ¿cómo funcionan estas construcciones de la realidad antes y después del golpe del 73 ?

Algunos autores, como Steve Stern, destacan el rol que jugaron los medios contra la dictadura, en su calidad de actores sociales, y en la construcción de una memoria. Otra -disidente a la oficial- que permitió levantar nuevamente una imagen de comunidad ${ }^{10}$. Sin embargo, la proclive homologación del medio no oficial, donde confluyen algunos medios de la industria cultural como también los medios locales y clandestinos, impide ver los matices de este proceso. No todos los medios actuaron ni se plantearon frente al régimen militar de la misma forma. Cada uno de ellos, desde sus respectivas plataformas de producción, diseñó sus propias estrategias políticas y comerciales que les permitió posesionarse de un lugar de enunciación determinado en el campo político. Para los medios disidentes, claramente consistía en denunciar y confrontar las políticas implementadas por la dictadura militar. No obstante, no tan solo de denuncias se sustentaban los medios, también estaba en cuestión la sobrevivencia a la crisis política del período.

Antes del golpe, la estructura de comunicación mediática era bastante heterogénea. Cada medio tenía sus propias características. A diferencia de la prensa escrita, que desde sus inicios estuvo ligada a la política, la radio tuvo siempre un carácter netamente comercial, es decir, fue concebida principalmente como un medio de entretenimiento, característica fundamental asociada a la cultura de masas ${ }^{11}$. Las programaciones, en este contexto, se iban adaptando tanto a los intereses de los

9 Rosalinda Bresnahan, "Radio and the movement in Chile 1973-1990. Independent and grass roots voices during the Pinochet dictatorship", Journal of radio studies, Vol 9, $\mathrm{N}^{\circ} 1$, Estados Unidos, 2002.

10 Steve Stern J., Battling for hearts and minds. Memory struggles in Pinochet's Chile, 1973 1988, Book two of the trilogy: The Memory box of Pinochet's Chile, United State of America, Duke University Press \& London, 2006.

11 Cfr. Martín-Barbero, Jesús. De los medios a las mediaciones, Bogotá, Convenio Andrés Bello, 2003 . 
receptores como a las distintas contingencias históricas y económicas. Así, los espacios informativos acapararon prontamente, junto con los de entretenimiento, un lugar fijo en la programación radial ${ }^{12}$.

Desde la década del sesenta se dio una tendencia progresiva hacia la democratización del orden comunicativo, lo cual llevó a que en 1973 se contara con un sistema de comunicaciones plural y abierto a todos los sectores de opinión ${ }^{13}$. Esto permitió incorporar a la población al debate informativo, haciendo disminuir considerablemente el problema de la exclusión en este ámbito ${ }^{14}$. En este proceso, la radio se constituyó como la tribuna política por excelencia, radializando a la cultura política. Todos los partidos y grupos políticos participaron, directa o indirectamente, del espacio radial: el Partido Comunista (Radio Magallanes), el Partido Socialista (Radio Corporación), los simpatizantes del gobierno de Allende (Radio Portales) el MAPU (Radio Candelaria), la Central Única de Trabajadores (Radio Luis Emilio Recabarren) y el MIR (Radio Nacional). De esta manera, a partir de las nuevas formas de jugarse la política en el espacio masivo, la radio reivindicó su lugar social como una forma efectiva de creación de opinión pública ${ }^{15}$. Esto, de hecho, no fue exclusividad de los medios que respondían a una lógica partidista, sino que el conjunto del espacio comunicacional se vio, de alguna forma, implicado en este proceso de politización del espacio público.

La radio Cooperativa, conocida como una de las emisoras con más trayectoria y con filiales en casi todo el país, fue vendida a principios de la década del setenta a la Sociedad Publicitaria y Propaganda Ltda., de la Democracia Cristiana. Este partido, que en ese momento solo contaba con un medio público de opinión (el diario La Prensa que tenía un fuerte corte político), consideró la importancia y alcance masivo que representaban las radioemisoras y optó por adquirir la radio. El directorio estuvo compuesto por Carlos Figueroa, Edmundo Pérez Yoma y Alberto Pulido, quienes además participan activamente en el terreno de los debates políticos del período.

A pesar de no instalarse como un medio politizado (a lo cual se negó el presidente del partido, Eduardo Frei Montalva), las tensiones sociales del momento permitieron que algunos de los programas de opinión de la radio constituyeran un espacio de denuncia en contra de la Unidad Popular. El programa que más impacto

12 Radio Cooperativa inicio sus programas informativos dos años después de su nacimiento. Panorama fue el primer programa de este tipo, a cargo de Juan Capbell y Emilio Filippi; Reportajes, a cargo de Hernán Millas y Rafael Otero; y, finalmente, en el año 1952 El Diario de Cooperativa, el primer informativo en Chile semejante a un diario. Archivo de la Radio Cooperativa Vitalicia. Historia General de la radio de divulgación pública, 2000. Para efectos del artículo, el siguiente archivo se expresará a través de la sigla ARCV.

13 Alfredo Riquelme, "El debate ideológico acerca de las Comunicaciones de Masas en Chile: 1953-1973", CÉNECA, Santiago, Agosto, 1984.

14 Eugenio Tironi y Guillermo Sunkel, "The Modernization of Comunications: The Media in the Transition to Democracy in Chile", en Democracy and the Media. A comparative Perspectiva. Editad by Richard Gunther and Anthonly Mughan, Communication, Society and Politics, Cambridge University Press, 2000, 165-193.

15 Carlos Catalán et al. "Transformaciones del sistema cultural chileno entre 1920 y 1973", CÉNECA, Santiago, 1987, 34 en adelante. 
ocasionó en este sentido fue "A esta hora las mujeres también improvisan”, dirigido por Raquel Correa, Patricia Guzmán, María Eugenia Oyarzún y Silvia Pinto ${ }^{16}$.

Con el golpe militar se quebró el sistema democrático de comunicación, que había caracterizado al país por más de cincuenta años. Los medios de comunicación se vieron afectados por una combinación de medidas como confiscaciones, restricciones legales y represión física a los periodistas y comunicadores, todos ellos dispositivos de censura que buscaban desmovilizar y despolitizar a la población ${ }^{17}$. La coartación de los medios continuó de manera drástica hasta la década de los ochenta, cuando estos se vieron controlados no solo por el gobierno, sino que también por la propia evolución y dinámica de los sistemas de comunicación masiva.

\section{DEL GOLPE A LOS OCHENTA}

Después del golpe militar, todos los medios de comunicación fueron intervenidos, sufriendo múltiples represiones, censuras y restricciones informativas ${ }^{18}$. Aquellas emisoras que no fueron clausuradas (como es el caso de Cooperativa), asumieron distintos roles en el contexto social de la época. Así, las radios Balmaceda y Chilena adoptaron un rol predominantemente político, al abrirse como plataforma de denuncia de los abusos que cometía el régimen ${ }^{19}$. En cambio, radio Cooperativa continuó en la lógica de los medios propiamente de entretención, lo cual se expresa por ejemplo en la incorporación de figuras representativas de la cultura de masas, tales como Antonio Vodanovic, Julio Martínez, Sergio Livingston, Juan la Rivera, César Antonio Santis, Javier Miranda y Gabriela Velasco, entre otros. Con ello, se apuntaba a una estrategia que eventualmente le reportaría a la radio mayores ingresos, que la sacarían de la crisis económica que arrastraba desde los años setenta y, a su vez, la protegería de las posibles represiones del oficialismo $^{20}$. Sin embargo, las violencias sociales que experimentaba el país, y el cierre de Radio Balmaceda con la consecuente relegación de Belisario Velasco en Putre, llevaron al medio a replantearse su objetivo central. De este modo, se vuelve a reabrir el 18 de noviembre de 1976 el espacio informativo "El Diario de Cooperativa", el cual había sido cerrado con posterioridad al golpe de Estado.

En esta nueva etapa del informativo, la directora fue la periodista Delia Vergara, ex directora de la revista femenina Paula, uno de los medios más progresistas vinculados a la inserción de la mujer en la sociedad chilena hacia finales de la década del sesenta. El programa contó con un conocido equipo de periodistas y

16 ARCV.

17 Stern J., op. cit., y Eugenio Tironi, op. cit., 165-193.

18 Durante la dictadura cuarenta comunicadores fueron muertos o desaparecidos, trescientos fueron exiliados y a más de mil se les prohibió ejercer su profesión. Hernán Uribe, "Prensa y periodismo político en los años 60/70, en E. Carmona (ed.) Morir es la noticia, Santiago, J\&C Productores Gráficos Ltda., 1988.

19 Rosalinda Bresnahan, op. cit., 163-164.

20 ARCV. Op. cit. 
comentaristas como Patricio Bañados (editorial), Alejandro Magnet (internacional), Jaime Hales (jurídico), René Cortázar (laboral), Mariano Silva (cine), José Luis Rosasco (libros), Juan Grau (ecología) y Patricia Politzer (política y economía). El objetivo era "establecer un noticiario de fuerte corte político que supliera la labor de Balmaceda" 21 . Si bien se podría pensar que este vuelco editorial respondía a un fin netamente político o partidista, el medio más bien buscó hacer prevalecer todos los principios éticos del periodismo informativo, esto es: dar a conocer los hechos de manera "objetiva" y pluralista. Pero, en ese momento, los "hechos" giraban en torno a los abusos y violencias cometidas por la oficialidad, por lo cual los noticieros cayeron en el tema más álgido de la agenda nacional: los derechos humanos $^{22}$ y las nuevas políticas económicas ${ }^{23}$.

Los informativos radiales contaban con la ventaja de poder relatar los hechos en la inmediatez en que estos ocurrían, y con comentarios que se sucedían a lo largo de las semanas, dependiendo del impacto que el tema pudiera ocasionar; es decir, la reiteración de la noticia o la sucesión de comentarios sobre ella tuvo por objetivo "crear" un tema en la opinión pública. Este formato noticioso, adjetivado, dejaba entrever las posturas y opiniones, tanto personales como corporativas, respecto de los acontecimientos presentes. Así, comentarios como los de Patricia Politzer expusieron y denunciaron la falta de humanidad en el modus operandi del régimen militar:

“...Para los destacados hombres públicos que firmaron esta declaración, fundamentalmente referida al caso Lonquén y al caso Letelier, esos delitos monstruosos no pudieron ser cometidos sin una honda degradación moral de los ejecutantes $\mathrm{y}$, de acuerdo a los antecedentes con que se cuenta, los firmantes presumen que existen responsabilidades en los niveles políticos de los cuales dependen los actores. Hoy, las palabras del General Fernando Matthei en relación a una guerra sucia constituye, hasta cierto punto, una aceptación de que en Chile se han violado los derechos humanos y se han registrado diversos actos que merecen ser considerados" 24 .

21 Entrevista a Genaro Arriagada. En Cristian Arismendi, Factores que incidieron en el aumento de sintonía de Radio Cooperativa entre los años 1980 y 1990, Tesis para obtener el grado del Licenciado en Comunicación, Santiago, Universidad de Chile, 1992, 15.

22 Si bien los abusos en materias de derechos humanos era evidente, no todos los medios daban cuenta de ellos, claramente su difusión respondía a una postura editorial, por cuanto los hechos también son una construcción discursiva en donde priman mecanismos de selección. En otras palabras, los "hechos" son construidos por el interés de quien formula la noticia: de quien decide lo que debe ser considerado noticia y qué no. Cfr. Teun van Dijk, La noticia como discurso. Comprensión, estructura y producción de la información, Barcelona, Paidós Comunicación, 1990.

23 Patricia Politzer, encargada de los informativos económicos, señala que este espacio se volvió en el gran frente noticioso para la crítica contra el régimen militar. Ella señala: "En ese terreno existían diferencias al interior de la propia dictadura y, por lo tanto, era un área en la que se podía opinar y enjuiciar las medidas que se adoptaban". Carolina Espinoza y Carlos Alzadora, Carlos. La verdad está en los hechos. 70 años de Radio Cooperativa, Santiago, Ediciones de Interés Público, 2007.

24 ARCV. Programa El Diario, Comentario de Actualidad Nacional por Patricia Politzer, 21 de marzo, 1979, Programación de las 07.00. Las cursivas no son del texto original. 
A su vez, Jaime Hales (comentarista judicial) denunciaba y cuestionaba tanto el accionar de la justicia chilena en la dictadura, como las políticas de impunidad instauradas a favor de las Fuerzas Armadas y de Orden en el país:

\begin{abstract}
"Buenos días. La noticia fue impactante el último viernes. El Ministro Bañados se declaró incompetente. Adolfo Bañados, Ministro de la Corte de Apelaciones de Santiago, conducía la investigación sobre el hallazgo de cadáveres en la mina abandonada de Lonquén. (...) Al avanzar en la investigación, el Ministro logró establecer, con un alto grado de seguridad, la identidad de los muertos. Se trataba de campesinos del lugar detenidos en 1973 por Carabineros y desaparecidos desde entonces. Eran personas cuyo desaparecimiento habían denunciado los familiares, parte de las listas que ha denunciado reiteradamente la Vicaría de la Solidaridad. Personas detenidas por Carabineros y de las cuales nunca más se supo. Y ahora aparecen enterrados en grupo, claramente con la intención de ser ocultados en una mina de cal abandonada. Y están muertos sin que aparezca su asesino. Y aunque aparezca, no habrá castigo porque hay una ley de Amnistía para todos los que cometieron homicidio desde 1973 hasta 1978, en marzo. Pero al menos el país debiera conocer el nombre de los culpables; de esos asesinos, aunque para ellos haya solamente una sanción moral, además -por cierto- de la obligación del homicida a indemnizar a la familia de las víctimas, responsabilidad que no desaparece con la ley de amnistía. ¿Cuál es el fundamento de la incompetencia del Ministro Bañados? Que aparecen directamente involucrados como autores miembros activos de las Fuerzas del Orden, es decir, Carabineros" 25 .
\end{abstract}

Las coberturas periodísticas de los casos más emblemáticos del periodo 26 y el carácter confrontacional de los comentarios informativos, tensaron las relaciones tanto con la oficialidad como al interior de la radio. Esto último se debió al choque que se produjo entre las figuras del ambiente masivo y los periodistas, quienes insistían en denunciar los hechos de abusos que se cometían en el país. Los primeros no veían bien que la emisora tomara una posición "partidista" respecto a lo que acontecía, por cuanto ello les creaba una "imagen de oposición" que era poco conveniente, si consideramos que muchos de ellos trabajaban también en otros espacios mediáticos (como la televisión), que se encontraban completamente intervenidos. Llamando a un ultimátum, el director de la emisora, Carlos Figueroa, en conjunto con el directorio de la Democracia Cristiana, decidieron a favor de los periodistas, ocasionando la salida de diversas figuras del entretenimiento a otros medios. Con esto se consolidaba el hecho de que la postura editorial que había asumido el "Diario de Cooperativa", no era tolerada por algunos de los colaboradores de la radio.

25 ARCV. Programa El Diario, Comentario de Justicia por Jaime Hales, el 9 de abril de 1979, Programación de las 07.00. Las cursivas no son del texto.

26 Entre ellos figuran los alegatos de extradición de Contreras y Espinoza por el homicidio de Orlando Letelier, la entrevista a Gustavo Leigh hasta el hallazgo de las osamentas de Lonquén. ARCV, Historia General de la radio de divulgación pública, 2000. AVSCH, Anuarios de Prensa y Causas Judiciales. 
Por otra parte, el descontento de la oficialidad con las emisiones del programa informativo quedó plasmado en permanentes presiones y amenazas por parte de la Dirección Nacional de Comunicación Social (DINACOS). En variadas ocasiones los miembros de la radio tuvieron que concurrir al edificio Diego Portales, para comparecer ante esta institución debido a los comentarios e informativos emitidos. El régimen daba por hecho que, detrás de Cooperativa, se había constituido una gran maquinaria política de oposición que ponía en riesgo al nuevo orden instaurado. Sin embargo, la situación de represión que experimentaban los medios y la sociedad en general impidió la constitución de redes efectivas que permitieran un acceso directo a las fuentes de información, sobre todo para un medio que funcionaba dentro de la lógica de mercado como era el caso de Cooperativa. Por lo mismo, era muy "difícil ubicar a los dirigentes por una razón evidente: ellos estaban en las catacumbas. Cuando uno de ellos emergía, uno partía a la entrevista" 27. A esto se sumaban los propios dispositivos de autocensura, que tenían por finalidad proteger a la emisora como testigo-víctima de la dictadura: esto era parte de la responsabilidad que tenía el medio consigo mismo, como mediador entre los hechos y el público. En suma, el imaginario conspirativo del régimen puso a Cooperativa como el "otro medio", uniéndolo simbólicamente a los grupos políticos opositores, lo que le significó el cierre de sus filiales en provincia en 1978.

El 15 de marzo de 1977 se promulga el Decreto Ley $N^{\circ} 1.762$, con el cual se crea la Subsecretaría de Telecomunicaciones ${ }^{28}$. Esta institución estaba encargada de la tuición y dirección técnica de las emisoras, y de establecer las pautas de funcionamiento de la industria mediática dentro del marco de la oficialidad. Cooperativa, desde los años de la Unidad Popular, venía solicitando una renovación de sus concesiones, lo cual había quedado sin resolver. Distintas son las versiones que existen respecto a este tema. Unos culpan al gobierno de la Unidad Popular por haberles negado las concesiones como un mecanismo de represión contra la Democracia Cristiana. Otros, en cambio, señalan que el régimen militar perdió los documentos correspondientes, aludiendo a que estos se habrían quemado durante el golpe, por encontrarse en La Moneda ${ }^{29}$. Para el caso, lo relevante es que, de una $\mathrm{u}$ otra forma, Cooperativa sufrió las represiones del régimen por su atrevimiento "a decir lo indecible". Se cerraron diez de sus estaciones regionales, permitiendo solo el funcionamiento de las que se encontraban en Santiago, Valparaíso y Temuco. Como consecuencia de ello, los avisadores se retiraron y la radio quedo prácticamente en la bancarrota al ver liquidados sus activos ${ }^{30}$. Pero, por otra parte, esta acción evidenció el temor que suscitaba en el gobierno la idea de un medio de comunicación que fuera capaz de reproducir los "errores" del sistema de comunicación democrático que había funcionado en Chile hasta 1973:

27 Arismendi, op. cit., 10

28 Publicado en el Diario Oficial del 30 de abril de 1977.

29 Existe una discordancia entre la versión de la radio hoy en día, y los testimonios de los protagonistas de aquel entonces recopilados por Cristian Arismendi. Por este motivo se adjuntaron ambas visiones. Ver ARCV (sin página) y Arismendi, op. cit., 12.

30 Lasagni, María Cristina et al. La Radio en Chile, Santiago, CÉNECA, 1988. 
"Lo único que la dictadura no estaba dispuesta a aceptar en ese momento era la libertad de expresión por una razón muy simple: los militares pensaron que uno de los factores más importante en la caída de Allende eran los medios de comunicación en absoluta libertad. Pero si en el tiempo de la UP, yo, en mi calidad de representante de la ARCHI, discutía las clausuras de radio Agricultura con el General Pinochet, quien era el jefe de la zona de Santiago. El era un hombre de confianza de Allende y por algo el Mandatario lo promovió a comandante en Jefe del Ejército" 31 .

Si bien la dictadura pensó que estos mecanismos de intervención traerían la muerte natural de la radio, ello no ocurrió. Por el contrario, con el cambio de directorio y las nuevas estrategias comunicacionales que implementó la emisora, esta logró consolidarse como el medio más creíble de los ochenta.

\section{El PROYECTO DE RADIO COOPERATIVA EN LOS OCHENTA}

Las condiciones poco favorables en que se encontraba Cooperativa con el cierre de sus filiales, la falta de auspiciadores y el bajo rating, llevaron al directorio a replantearse sus objetivos editoriales con el fin de asegurarse una permanencia en el mercado mediático ${ }^{32}$. El primer cambio que permitió redefinir los criterios de la emisora se produjo al interior del directorio. La presidencia la asumió Genaro Arriagada, y la gerencia pasó a manos de Luis Ajenjo ${ }^{33}$. Ellos centraron su cometido en generar las condiciones que permitieran atraer a un público masivo; es decir, crearon un producto mediático nuevo, que interpelara a todas las necesidades de la sociedad civil, con el fin de atraer una cantidad mayor de oyentes. Para el directorio, la radio era un medio que estaba por sobre las coyunturas políticas del momento, y que había ganado su autonomía desde muy temprano en la historia de las comunicaciones en Chile. Por lo mismo, debía ser un medio profesional, plural, independiente y objetivo, y no una plataforma de lucha política como lo eran otros medios. A este respecto Genaro Arriagada director de la emisora señala:

"La radio nunca tiene que jugarse. Qué es esto de jugarse... aquí cada uno cumple su rol en la sociedad chilena. Había unos que lo cumplían cabalmente, la Vicaría de la Solidaridad, los Colegios Profesionales. Pero nada se juega al todo o nada. Eso no existe en la vida. Lo importante es que exista un trabajo profesional, plural, independiente y objetivo. Aquí está la verdad ante todo, duela a quien duela"34.

De esta manera, al plantear su discurso desde la retórica de la objetividad periodística, la emisora podía consolidar su autonomía respecto de las posiciones

31 Ibidem, 13.

32 El rating de audiencia para 1980 era de 0.8 puntos, considerablemente más bajo respecto a 1977, cuando la radio alcanzaba un rating de 6.9 puntos de audiencia. Stern, op cit., 302.

33 ARCV, Historia General de la radio de divulgación pública, 2000.

34 Arismendi, op. cit., 16 . 
partidistas en el espacio público, lo cual será clave para asentar una imagen de credibilidad entre los auditores. Por otra parte, esta autonomía le permitirá también a la radio cierto margen de libertad respecto de las regulaciones estatales, a partir de lo cual podrá permanecer dentro del espacio de oposición política, como un medio no oficial.

A partir de este objetivo, se buscó desarrollar nuevas formas y estilos que diferenciaran a la emisora de los otros medios, principalmente de aquellos considerados panfletarios ${ }^{35}$. Se eliminó todo el estilo confrontacional sostenido a través de los comentarios editoriales y noticiosos que habían caracterizado a la emisora en los últimos cuatro años de la década del setenta, y se ordenó una nueva programación a Ernesto Molina, director de la agencia de publicidad TEMPORA, quien reestructuró la radio con el fin de ver los frutos en los primeros cinco años de la década del ochenta.

El sistema que operó fue el de continuidad, también conocido como "modular", en el cual las programaciones se componen de pequeños "módulos" o elementos repetitivos que se suceden en la difusión de información diaria, como por ejemplo: cortinas informativas, música, señal horaria, etc. El cuerpo fundamental lo constituía el bloque informativo, representado por "El Diario de Cooperativa", cuyo fin era dar a conocer los hechos que acontecían en el momento. De esta manera, la política quedaba soterrada en el hecho mismo.

Los espacios noticiosos se hicieron más frecuentes. Además de los tres bloques de informativos que se iniciaban a las seis de la mañana, se incorporaron flashes noticiosos que se emitían a lo largo de todo el día y que interrumpían la programación. A esto se sumó el empleo del móvil matinal, adelanto tecnológico que cambio la forma de informar de la industria mediática. Este sistema consistía en la transmisión directa desde el lugar de los acontecimientos, es decir, la información provenía de la boca misma del reportero, quien se identificaba con su nombre y apellido frente a todos los oyentes. Esto le otorgó a la noticia un toque más "humano" y un efecto de inmediatez que permitió el acercamiento al público. Por otra parte, el apoyo de los locutores fue clave. Ellos eran la voz oficial y autorizada, los que inscribieron el tono y el ritmo de la emisora en las memorias colectivas. Las voces de Gema Bravo, Manola Robles y Sergio Campos destacaban en medio de una cortina de tambores que anunciaban que algo estaba ocurriendo ahí, en ese minuto, algo que, dicho por la boca de los conductores, se transformaba en "verdad": A esto se sumaban las frases emblemáticas que sintetizaban el estilo del medio, y que se transformaron en el sello de los noticieros. En ellos se evidencia el tipo de periodismo que la emisora decidió trabajar, en donde los "hechos" de todos los sectores encontraban su tribuna. Entonces, eslóganes como: "Usted tiene derecho a saber la verdad y la verdad está en los hechos", "Todo se puede decir si sabe cómo decirlo", "Esta no es noticia si no lo emite Cooperativa”, permitieron crear una imagen de credibilidad del producto informativo, que estaba en plena

35 Por medios panfletarios se entiende todos aquellos sistemas de comunicación que poseen una fuerte connotación ideológica, y cuya circulación generalmente se reduce a una comunidad específica. 
concordancia con el espacio ideológico que pretendía abarcar la organización de noticias: como estrategia pro democracia y como sustento comercial.

Con el fin de lograr un mayor grado de verosimilitud a partir de un periodismo basado en los "hechos", Cooperativa incorporó los discursos de las víctimas y también de los victimarios, revelando de esta manera lo que pasaba tanto entre las personas que sufrían persecución como entre quienes diseñaban las políticas. Para esto, se establecieron instrucciones precisas de corte burocrático, que permitieron constituir redes y circuitos informativos. De esta manera, los periodistas podían acceder a la información y dar a conocer los hechos dentro de los marcos establecidos, sin que ello significara un riesgo tanto para los informantes como para la emisora.

"Para nosotros como radio era muy problemático recibir a una mujer que, llorando y angustiada, nos comunicaba que su marido había sido secuestrado por la CNI. Eran verdaderas súplicas. Ese cuadro para nosotros era un problema casi insoluble. Por una parte no teníamos los medios para pesquisar lo que había pasado, y por otra esa mujer podía ser enviada por los servicios de seguridad con la intención de que la radio diera una falsa noticia. Es decir una trampa"36.

El actuar de Cooperativa, por otro lado, le significó a la emisora asumir los embates y rigores que su posición le había procurado como medio opositor. La institucionalidad aplicó distintas políticas de exclusión, como la negación de los permisos para asistir a las rondas de prensa del gobierno -en donde Pinochet o la autoridad respectiva entregaban su versión de los hechos-, o a las comitivas que acompañaban a las giras oficiales. Sin embargo, el mayor problema lo representaban los propios colegas partidarios del régimen. La mayoría de ellos veía un paralelo entre su supervivencia y la dictadura, llegando a trabajar en ambos espacios simultáneamente: para el medio y para el gobierno. No era difícil encontrar a un periodista de algún diario trabajando de asesor para el Ministerio del Interior, o a algún medio como sucursal del Ministerio de Secretaría General de Gobierno ${ }^{37}$. Fueron ellos, "los colegas", quienes se encargaron de tutelar y restringir la información a la radio.

Como una medida precautoria, la oficialidad diseñaba de antemano las pautas de preguntas, de forma tal que ellas se enfocaran solamente en las obras y proyectos del régimen. Esto significó diseñar estrategias comunicativas a partir de códigos que rompieran el cerco informativo instaurado, y en el cual la noticia saliera de la misma voz de la autoridad. Estas estrategias consistían en formular las preguntas lo más abiertas posible, sin entregar datos específicos.

"Periodista: Ministro, ¿el gobierno ha tomado las medidas para evitar desordenes el día de la protesta?

Ministro: Bueno, mañana habrá un gran despliegue policial en las calles.

36 Arismendi, op. cit., 27

37 Ibidem, 30. 
Informe de prensa: El Ministro informó que mañana habrá un gran despliegue de carabineros, ante los llamados a protesta nacional" 38 .

Así, la emisora entregaba los datos necesarios de la información, pero permitía también realizar una segunda lectura, desde la cual los auditores podían deducir tanto los lugares de encuentro como las advertencias para los organizadores y participantes de las protestas. De esta manera, los dispositivos discursivos que eran constitutivos de la dialéctica informativa de neutralidad, generaron una identidad política de oposición al interior del discurso de la emisora.

En 1985 los estudios de mercado señalaron que Radio Cooperativa era la emisora más escuchada en el país, superando a Radio Portales ${ }^{39}$. Este éxito rotundo, que se comienza a percibir desde el ochenta y tres, se debió no tan solo a lo que se decía, sino también a cómo se lo decía: formas y conceptos, que se sumaban, un paquete periodístico en el que intervenía la voz, el profesionalismo, la presentación de la información, etc. Todo lo imprescindible para que la emisora fuese atractiva, distinta y "creíble".

\section{ENTRE TÁCTICAS NÁUTICAS Y DE CONSENSOS: LA CONSTITUCIÓN POLÍTICA DE 1980, LAS PROTESTAS NACIONALES Y LAS CLAUSURAS}

Entre 1981 y 1982 se comienza a evidenciar una de las mayores crisis del régimen militar, motivada por factores económicos y políticos que permitieron modificar y diversificar las formas de oposición, a partir de la reorganización del espacio público, del monopolio moral que la oposición empezaba a manifestar en torno al tema de los derechos humanos y de la "repolitización" de ciertas instituciones culturales como las universidades y los espacios educativos. En este contexto, los medios de oposición cumplieron una función prioritariamente política.

La información se ordenó de acuerdo al juego de demarcaciones posicionales en que se expresaban "las políticas de la palabra", con el objeto de construir identidades y alimentar estrategias competitivas en el campo de la oposición ${ }^{40}$. Así, las denuncias vuelven a adquirir un papel relevante, especialmente en el terreno de los derechos humanos, y se vuelven ahora más públicas y con un impacto mayor. Sin embargo, esta acción política de los medios carecía de un centro aglutinador y de una planificación clara; fueron, más bien, "tácticas", es decir, "intervenciones marginales dentro de circuitos cuya operación depende siempre de unas condiciones básicas y previas, como puede serlo la autonomía y organización de las instituciones centrales que inciden en cada circuito"41. Este fue el caso de Cooperativa.

\footnotetext{
38 Entrevista a Guillermo Muñoz, jefe de prensa de la radio. En Arismendi, op. cit., 46.

39 Stern, op. cit., 303.

40 José Joaquín Brunner, Un espejo trizado. Ensayos sobre cultura y políticas culturales, Santiago, FLACSO, 1988, 127-128.

41 Ibidem, 129.
} 
Con el cambio de formatos y estilos, la emisora se consolidó como un medio creíble y, además, se aseguró un espacio de autonomía en relación a los partidos. Así, la radio se hacía responsable de sí misma y de sus informativos. Si bien las noticias giraban en torno a las tensiones sociales y políticas de los ochenta, esta manifestó una posición ambigua frente a la oficialidad, lo cual le permitió seguir en el mercado mediático. En otras palabras, adoptó -de acuerdo a las circunstancias- dos posiciones: la "náutica" y la de los consensos. La primera aludía a los mecanismos de autocensura que aplicaban los directivos de la radio, cuando veían que la cobertura de ciertos acontecimientos podía poner en riesgo a la emisora, lo cual implicaba callar ciertos hechos y adoptar una postura más ambigua una vez que veían los resultados de ciertos informativos. Un caso memorable fue la cobertura al plebiscito de la Constitución de 1980. Por otra parte, las políticas de consensos implicaron pactar de antemano con la oficialidad la forma de emitir ciertos informativos con el fin de resguardar la continuidad del medio en el dial.

\section{La Constitución de 1980: de la oposición a la táctica "naútica"}

El 11 de agosto de 1980 se anunciaba en los medios el llamado a plebiscito para aprobar la Carta Fundamental redactada por colaboradores cercanos al régimen militar. Desde ese minuto, los pronunciamientos, comentarios y declaraciones desde distintos sectores sociales no dejaron de sucederse. Más allá de informar sobre la noticia, Cooperativa construyó una campaña de rechazo, llamando implícitamente a votar NO en dicho plebiscito. Esta campaña estuvo presidida por el director de aquel entonces de la radio, Genaro Arriagada, y en ella participaron diversos miembros de la Democracia Cristiana, el directorio, y todos los integrantes de la emisora (periodistas, administrativos, colaboradores, etc.) ${ }^{42}$. Así, los espacios informativos se inclinaron a emitir opiniones y noticias contrarias a la promulgación de la Constitución, lo cual no significó que las noticias desde el gobierno desaparecieran. De esta manera, la radio, a través de los informativos, dio cabida a todos los actores sociales del momento.

"El anuncio hecho por el general Pinochet, sometiendo la Constitución a plebiscito, lo considero un insulto y una provocación a los chilenos. Lo que se pretende es una farsa y un fraude (Declaración de Andrés Zaldívar. Emisión del 12 de agosto de 1980).

La Agrupación Cultural Universitaria, ACU, hizo un llamado a todos los universitarios del país para que discutan y elaboren una posición unitaria frente al plebiscito del 11 de Septiembre (Emisión del 18 de agosto de 1980).

El grupo de los 10 llamó públicamente a todos los sectores, para la constitución de un comando para la restitución de la democracia” (Emisión del 19 de agosto).

42 "Yo había sido jefe de esa minúscula campaña. Muchos ejecutivos de la radio y del directorio habían participado activamente contra la Constitución que aprobó Pinochet. Tras el triunfo del gobierno, le comunico al jefe de prensa y al gerente bajar el periscopio y sumergirse...". Ibidem, 45 . 
"La Federación Campesina e Indígena de Sindicatos Agrícolas de la provincia de Santiago, dijo que el llamado a plebiscito hecho por el General Pinochet, es un atropello al pueblo chileno (Emisión del 20 de agosto de 1980).

Los Centros de Alumnos Democráticos de la Universidad Católica, señalaron que el plebiscito es una indignidad política y moral (Emisión del 21 de agosto de 1980).

El Rector de la Universidad de Chile suspendió un foro sobre el llamado a plebiscito y la constitución programado por el Centro de Alumnos de Ciencias que se iba a realizar en el Campus Macul (Emisión del 22 de agosto de 1980).

El obispo auxiliar de Santiago, Monseñor Jorge Hourton, señaló que es contraria al magisterio de la Iglesia la tesis expuesta por profesores de Derecho de la Universidad Católica, que apoyan al plebiscito gubernativo (Emisión del 4 de Septiembre de 1980).

Un total de 54 personas fueron detenidas por realizar manifestaciones contrarias al plebiscito en el centro. Hasta el momento el número de personas detenidas por efectivos policiales llega a unos 54 que se dividen en 45 hombres, un menor y 8 mujeres. Mucha gente solidarizó con los manifestantes aplaudiendo y gritando al unísono, NO-NO-NO" (Emisión del 9 de septiembre de 1980)"43.

Todos los sectores de oposición fueron cubiertos por las transmisiones informativas, a través de sus propios comentarios, alegatos, denuncias de amedramientos, detenciones por llamar a votar NO, comentarios callejeros, etcétera, con lo cual se dejaba entrever la posición adoptada por la emisora. Atrás quedaba entonces el discurso de objetividad periodística que había sustentado la emisora como principio. Sin embargo, con posterioridad a la aprobación de la Constitución, la emisora se sumergió inmediatamente en el silencio, provocando el enojo de los colaboradores de la radio, quienes creían que era el minuto de seguir adelante con la campaña de oposición política, de lo contrario, esta habría consistido solo en un acto efímero de heroísmo que conmovió al país durante una semana. Este conflicto requirió de la intervención de Genaro Arriagada, quien ordenó bajar el periscopio,

"Ustedes son los periodistas, pero yo soy el conductor político de esto, en consecuencia mi instrucción fue bajar el periscopio". (...) "En efecto, nos sumergimos, y a la semana de la discusión fue expulsado del país Andrés Zaldívar, presidente de la DC. Bueno, los periodistas vinieron y reconocieron su error del diagnóstico político y dimos por superado el punto" 44 .

\section{Entre protestas y clausuras: la táctica de los consensos}

La crisis económica desatada en 1983 como consecuencia de la implantación de las políticas neoliberales, y la consiguiente pauperización de distintos sectores sociales, pusieron en jaque al nuevo orden que la oficialidad implementó desde

43 Todas las emisiones sobre la Constitución del 80 se encuentran en los registros de prensa de la Vicaría de la Solidaridad. AVSCH, Anuario de Prensa, 1980. "Sobre el plebiscito: 9 de agosto al 23 de Octubre".

44 Ibidem, 45. 
1977, y que había sido ratificado con la Constitución de 1980. La agitación social se hizo sentir en todos los sectores sociales, no tan solo en los populares. Se produjeron varias olas consecutivas de protestas, que acabaron por despertar la violencia y represión por parte de la oficialidad. Uno de los sectores más afectados fue, nuevamente, el de los medios, los que vieron clausuradas e intervenidas sus comunicaciones por tiempos más largos. Se les acusaba de ser los responsables de alentar a las masas y de sentar las bases para la caída del gobierno ${ }^{45}$.

La crisis del nuevo orden del régimen permitió que los medios se aprovecharan de las fisuras y volcaran toda su artillería discursiva en la palestra pública:

"Los medios comenzaron a atreverse y allí nosotros, que veníamos de un periodo delicado, entramos en la misma...En términos económicos todo el mundo entra en la pelea. Allí el gobierno estaba en una situación muy débil. Por eso vinieron las protestas el 83. El país empezó a constatar problemas graves en la conducción. Un Ministro de Hacienda que le tiró una cadena a la banca privada. Aquí se nos olvida que incluso el superintendente de bancos fue detenido, etc., etc. En esas aguas tú te podías atrever a todo lo que quisieras. Allí nos envalentonamos" 46 .

Así, el rol de mediador transformó a la radio y a los otros medios de comunicación en actores sociales -con excepción de la televisión y del diarismo-, en la medida en que los discursos informativos que ellos emitían permitieron mostrar el sufrimiento de una comunidad mutilada y reprimida. Los medios, de este modo, permitieron visibilizar una memoria disidente que activaba la práctica de "vencidos", una memoria que muchos se negaban a ver, y la cual había sido silenciada por la oficialidad.

El 11 de mayo de 1983, Luis Ajenjo, gerente general de la emisora, se encontró, camino al trabajo, con una manifestación en la calle Flemming, en la comuna de Las Condes. Comenzó inmediatamente una transmisión en directo, con la ayuda de los propios manifestantes. El resto de los periodistas se movilizaron a otros puntos de la ciudad donde también se estaban gatillando las movilizaciones. Fue allí, recuerda Ajenjo, cuando Sergio Campos se consolidó como la voz de Cooperativa. Esa primera transmisión creó un aumento significativo de audiencia. Los teléfonos no paraban de sonar, estableciendo una relación directa con sus oyentes, quienes suplieron la falta de personal de la emisora. Cuatro días después vino la primera clausura, bajo la orden del Ministro Secretario General de Gobierno, Ramón Suárez ${ }^{47}$.

45 Entre 1983 y 1984 se clausuraron diversos medios tanto escritos como radiales. Dentro de los casos más relevantes consta el cierre de la revista Apsi (diciembre de 1982), el de la revista Análisis (septiembre de 1983), que incluyó el presidio de su director Juan Cárdenas, y el de las radios Cooperativa (mayo de 1983 y septiembre de 1984) y Chilena (septiembre de 1984). A esto se suma la clausura de emisoras regionales y vecinales. Stern, op. cit., 298-308.

46 Ibidem, 49.

47 La cobertura de las protestas del 83 dejaron a Cooperativa liderando el rating de sintonías. Además, superó en credibilidad a los diarios y revistas ubicándose en el $41 \%$ de los medios más creíbles del minuto. Stern, op . cit., 303. 
Según la opinión de los miembros de Cooperativa, las movilizaciones que se realizaron en los barrios medios-altos de la ciudad (como Las Condes, La Reina, Ñuñoa o Lo Barnechea) fueron determinantes en el desenlace de las restantes movilizaciones. A nuestro parecer, esto evidencia el malestar nacional que bullía entre todos los miembros de la sociedad, pero puede ser muy arriesgado cargar toda la responsabilidad de las protestas a un solo sector social, y negar el rol que, desde el golpe militar, cumplieron tanto los sectores populares como las agrupaciones políticas y sindicales. Sin embargo, esta visión que da Cooperativa puede también ser interpretada como una forma de interpelar al público masivo que constituía sus potenciales oyentes. Refiriéndose a la primera protesta, Genaro Arriagada señala: "Si bien la convocó Seguel el movimiento lo vimos en el barrio alto. Ya en la segunda, se agregaron los sectores populares. Allí lo sectores oficialistas advirtieron que eso podía provocar la caída del régimen. Entonces los medios, que en un principio fueron casi todos en la primera protestas, se descolgaron rápidamente" 48 .

La cobertura noticiosa de las protestas le significó un alto costo a la emisora: la clausura que esta sufrió en 1983 tuvo una doble significación para el medio. Desde un punto de vista comercial, los avisadores -que en su mayoría se encontraban repactando las deudas ocasionadas por la recesión- se negaban a invertir en un medio que no ofrecía seguridades debido a su rechazo por parte de la oficialidad. Por otra parte, las transmisiones de las protestas le permitieron a la radio posesionarse como el medio más creíble por parte de los auditores. El aumento de sintonía fue notorio, llegando a desplazar a Radio Portales. Cartas, llamados telefónicos, e inserciones en otros medios escritos, dejaron ver y sentir el apoyo nacional a la labor de los periodistas de la radio. Cooperativa se había transformado en "la radio oficial de las protestas", a pesar que ellos niegan hasta hoy a esa atribución.

"Estimado señor Director:

En el Chile actual ya nada puede asombrarnos, pero sí, indignarnos.

Sé que muy poco o nada servirá el hecho de demostrar, como una dueña de casa más, mi más absoluta solidaridad y completo apoyo a los abnegados trabajadores de Radio Cooperativa, la cual fue silenciada, justamente, horas antes de celebrarse el DÍA DE LAS COMUNICACIONES SOCIALES. ¡Qué sarcasmo!

Somos muchos los chilenos que deseamos a nuestro Chile, paz, tranquilidad y sobre todo justicia verdadera y no más arbitrariedades y represiones absurdas, como actualmente está sucediendo" 49 .

Las cartas de apoyo afianzaban el respaldo nacional a la labor de la emisora. Ellas demuestran que la radio se instalaba en las memorias de los sujetos, a partir de sus formatos y estilos de comunicación e información periodística, reafirmando y reconstruyendo la noción de comunidad entre sus auditores. Cooperativa intervenía directamente en la vida cotidiana, transformándose en parte de sus vidas.

48 Ibidem. 49.

49 L.G.C. "Adhesión a Cooperativa”, Hoy, Santiago, Cartas al Lector, 8 al 14 de junio de 1983, 70. 


\begin{abstract}
“Estimado Señor Director:
“(...) Desde entonces oigo dicha radio, en la mañana desde las 7 AM hasta que termina, luego en mi casa o auto, siendo por ende la radio que escuchan mis hijos, nueras, etc. No la cambio por otra por su música, por la voz de sus locutores, por sus noticias al minuto y desde el lugar mismo, por lo completo del Diario de Cooperativa, por la objetividad en sus informaciones, etc. ${ }^{50}$.
\end{abstract}

La emisora recibió durante su clausura alrededor de tres mil cartas y mensajes de apoyo, las cuales corroboraban que el propósito instalado desde los años ochenta -cuando se cambiaron los estilos y formatos bajo la dirección de Genaro Arriagada- había tenido efectos positivos para la estación. Cooperativa se había transformado en la radio de "todos los chilenos". El Congreso Nacional de Comunicaciones de 1985, realizado en Viña del Mar, vino a reforzar esta situación. En las jornadas, en las cuales participaron distintos activistas poblacionales, comunicadores, políticos de todos los partidos de oposición y estudiantes, se discutió sobre la constitución de nuevas políticas de comunicación social y, tanto en los trabajos grupales como en los análisis cualitativos, se dejaba entrever que Cooperativa era la única de las emisoras por la cual se sentían interpelados todos los participantes, la única radio "que dice la verdad de manera objetiva", "que da cuenta de todo lo que acontece" 51 .

Frente a los decretos de clausura emitidos por el régimen en contra de los medios, se aplicó tanto una estrategia jurídica como una acción de denuncia a través de los propios medios de comunicación. Se formaron comités de defensa de la radio, integrados por personalidades del mundo profesional y artístico. Así como los dispositivos jurídicos permitieron contrarrestar las medidas de censura, los diálogos que se entablaron entre el gobierno y los altos cargos directivos de los medios permitieron también llegar a acuerdos provisorios respecto a levantar las clausuras antes del fallo de los tribunales, o a consensuar la información a emitir. La justificación de este actuar se centraba en que “"a ellos” (los militares) no les convenía que un fallo de los tribunales declarara que ellos no tenían facultad para clausurar a la emisora ni mucho menos en el caso de una clausura preventiva" 52 .

A este respecto, Carlos Figueroa evoca; "Uno de los casos que recuerdo fue con Márquez de la Plata. Conversamos que la clausura iba a durar, por ejemplo, hasta el sábado. Ustedes, nos decía, el lunes se desisten del recurso de protección. Claro, así negociábamos" 53 . Esta forma de relacionarse se debía, en gran parte, a las redes que existían desde antes del golpe, a lo que se sumaban ahora las propias dinámicas de relaciones con los miembros del gobierno.

50 María Gallardo R. "Radio Cooperativa", Revista Hoy, Santiago, Cartas al Lector, 25 al 31 de mayo de 1983, 65 .

51 Comunicación Hoy y Futuro. Actas del III Seminario Nacional de Comunicaciones. Organizan: Colegio de Periodistas de Chile, TIAC, ICECOOP, CENECA, CED, CEDAL, ECO, ILET, IPS, INPRODE, Centros de Alumnos de la Escuela de Periodismo de la Universidad de Chile y la Pontificia Universidad Católica. Agosto-Noviembre, 1985.

52 Arismendi, op. cit., 50.

53 Ibidem, 52 
Parte de las políticas de consenso entabladas entre el medio y el régimen -para evitar los riesgos de ser cerrados definitivamente- lo constituyó el recorte de los informativos de la emisora, por cuanto se consideraba que estos eran el vehículo que alentaba a las masas a seguir luchando por sus demandas. Al fin y al cabo, como señaló en su minuto Márquez de la Plata: "Protesta sin radio no era protesta" 54 .

Al interior de la radio estas decisiones produjeron tensiones entre sus miembros. Los periodistas consideraban que la emisora debía dar una lucha directa en contra del régimen y no consensuar pactos con él, sin embargo, las decisiones del directorio dejaban entrever que el objetivo radial era otro. Para estos últimos, cada cierre era interpretado como una derrota, pues sabiendo las reglas del juego y toda la arbitrariedad que existía, ellos ponían en riesgo a la emisora y la estigmatizaban como una radio política. A su vez, los partidos de oposición también confrontaron a la emisora. Frente a las medidas precautorias que adoptó la radio, los partidos de izquierda consideraron que Cooperativa no estaba cumpliendo con su función ética (y política) fundamental: informar.

“...nos trataron de cobardes, porque simplemente cuando las protestas ya no tenían un gran efecto nosotros informábamos tal como eran. Una anécdota. Una vez en una reunión del Partido Socialista arreciaron las críticas contra nosotros. Allí, lo sé porque estaba Ángel Flisflich, predominó la idea de algunos dirigentes que impusieron el criterio de que nosotros en la radio teníamos derecho a juzgar la labor de la radio desde nuestras casas. Ese fue el argumento" 55 .

En 1986 la radio llevó a cabo una encuesta, para saber la sensación de la opinión pública respecto al estado de sitio y a las protestas. Los resultados sorprendieron tanto a los miembros de la emisora como a los grupos de oposición: "la gente estaba cansada de las protestas..."56. La encuesta señalaba que la gente estaba harta de tanta represión, de los allanamientos de madrugada en los sectores populares, y de la violencia que cobraba sus víctimas en todos los sectores. Frente a tales resultados, la emisora -siguiendo con el postulado central de sus programaciones, el de informar- comunicó esta noticia, recibiendo toda la artillería de la dirigencia política de izquierda. La radio, al hacer público el cansancio nacional frente a la violencia, desarticulaba las estrategias de los partidos políticos para contrarrestar al gobierno de Pinochet, y dejaba en evidencia la incongruencia de estas prácticas de resistencia con lo que pensaba la opinión pública.

"Claro. Protestar en el barrio alto era más cómodo sin dejar de ser peligroso. Pero a fin de cuentas nadie te sacaba a las cinco de la mañana desnudo y te formaba en una plaza a la intemperie. Eso creo fue una muestra de independencia de la emisora de las estructuras políticas. También fue nuestro compromiso con el público, señala Ajenjo"57.

$54 \quad$ Ibidem, 52

55 Ibidem, 53.

56 Ibidem, 58 .

57 Ibid. 
Así, Cooperativa dejaba establecido su lugar como medio autónomo dentro del espacio de la oposición, en la medida en que no se comprometía orgánicamente con el movimiento social articulado por los grupos políticos en los ochenta. Esta autonomía del medio, sin embargo, no significa que la radio se situara únicamente en el espacio de la "entretención", puesto que manifestaban un compromiso claro (aunque no orgánico) con las directrices políticas que dirigirían los procesos de redemocratización y, principalmente, con el imperativo que les exigía su posición de mediadores entre los hechos y la opinión pública: la labor de la radio es informar.

\section{A MODO DE CONCLUSIÓN}

Durante la dictadura, Radio Cooperativa y otros medios de oposición construyeron una imagen de Nación Otra, a partir de las memorias disidentes a la dictadura. En ellas las masas reconocieron sus demandas, vivencias y modos de expresión con lo que se logró consolidar una identidad cultural compartida distinta a la del régimen militar. En gran parte, esto se debió a que la emisora consolidó un discurso autónomo de la política partidista, exponiendo los sucesos de manera tal que producían un efecto de realidad compartido por todos los miembros de la sociedad chilena que se sentían interpelados por el discurso radial. Para esto, dispuso de ciertas ventajas tecnológicas que le permitieron sobrepasar los prejuicios socioculturales de grupos particulares, permitiéndole asentarse como el medio más creíble y masivo del período. Así, el discurso informativo radial de Cooperativa se consolidó como un discurso nacional que, si bien no iba dirigido a "todos los chilenos", era aceptado por lo menos por gran parte de la comunidad, incluso por aquellos que no necesariamente se sentían identificados con el medio.

El discurso informativo de la radio estuvo mediado por distintos factores, propios del juego hegemónico que se experimentaba en ese momento: la relación de la emisora con el partido, las relaciones internas entre directivos y subordinados, la relación con el mercado y con la misma oficialidad, fueron los elementos que fijaron y determinaron el camino a seguir. De esta manera, intentar establecer la responsabilidad del medio durante la dictadura se vuelve complejo, puesto que, como se expuso en este trabajo, las representaciones producidas por Cooperativa siempre dependieron de unas condiciones básicas y previas que incidieron en la circulación de la información. Ello, además, sin considerar que la recepción de los mensajes emitidos por la radio dependían siempre, en última instancia, de la interpretación que los propios oyentes realizaban de lo que la radio pretendía comunicar. 